American Journal of Applied Sciences 5 (8): 943-951, 2008

ISSN 1546-9239

(C) 2008 Science Publications

\title{
Heuristic Algorithm in Optimal Discrete Structural Designs
}

\author{
Alongkorn Lamom, Thaksin Thepchatri and Wanchai Rivepiboon \\ Faculty of Engineering, Chulalongkorn University, 10330, Thailand
}

\begin{abstract}
This study proposes a Heuristic Algorithm for Material Size Selection (HAMSS). It is developed to handle discrete structural optimization problems. The proposed algorithm (HAMSS), Simulated Annealing Algorithm (SA) and the conventional design algorithm obtained from a structural steel design software are studied with three selected examples. The HAMSS, in fact, is the adaptation from the traditional SA. Although the SA is one of the easiest optimization algorithms available, a huge number of function evaluations deter its use in structural optimizations. To obtain the optimum answers by the SA, possible answers are first generated randomly. Many of these possible answers are rejected because they do not pass the constraints. To effectively handle this problem, the behavior of optimal structural design problems is incorporated into the algorithm. The new proposed algorithm is called the HAMSS. The efficiency comparison between the SA and the HAMSS is illustrated in term of number of finite element analysis cycles. Results from the study show that HAMSS can significantly reduce the number of structural analysis cycles while the optimized efficiency is not different.
\end{abstract}

Key words: Heuristic algorithm, steel design, optimization algorithm

\section{INTRODUCTION}

There are many techniques used to handle structural optimization problem. Deb and Gulati ${ }^{[1]}$ proposed techniques to design truss structures for minimum weight using genetic algorithm. Shan and Huanchun ${ }^{[2]}$ combined two algorithms to handle the discrete optimization of structures. Chen ${ }^{[3]}$ used the SA to place active passive ${ }^{-1}$ member in truss structures. Szewczyk and Hajela ${ }^{[4]}$ incorporated the SA and counter propagation neural network to perform structural optimization. Benage and Dhingra ${ }^{[5]}$ proposed three strategies in using the SA to solve single and multi-objective structural optimization problems. Chen and $\mathrm{Su}^{[6]}$ suggested two methods to improve $\mathrm{SA}$ efficiency in optimal structural designs. Although these referenced techniques can be used to handle structural optimization problem, large numbers of finite element analysis are needed to improve the result. The main problems of using huge number of finite element analysis cycles are that many rejected answers are generated. Consequently, a waste of computer time occurs.

Although the SA is a simple and quite easy technique for implementation, there are many function evaluations needed to find optimal answers in structural optimization problems. Since possible answers given by the SA are randomly generated, the percentage of accepted answers is low. Only answers which pass constraint checks are kept. Many generated answers, of course, are rejected because they do not pass constraints. These constraints, known as filters, involve member abilities to support both tension load and compression load. After possible answers are filtered by constraints, the best answer is searched. A typical optimization problem is modeled as shown in Fig. 1.

Theoretically, the probability to generate a new answer at the left hand side and right hand side of the current answer is equal. In structural optimization problems, however, the typical optimized algorithm can be modified to reduce the computation time. In this study, the problem understanding is used to help developing the new algorithm, the HAMSS. Because the structural analysis process spends most of the

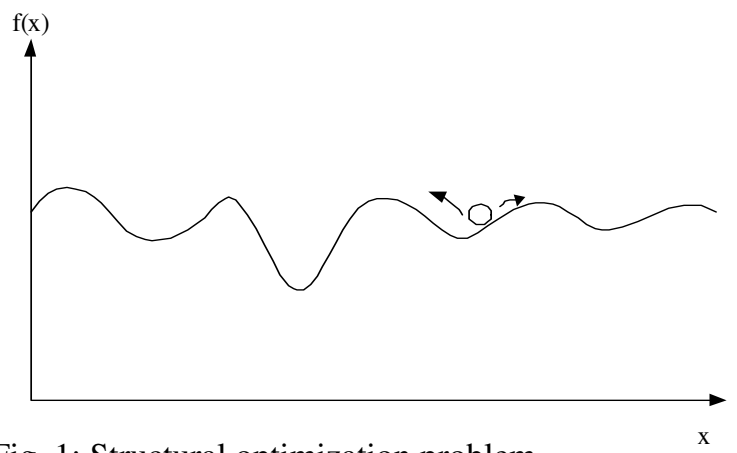

Fig. 1: Structural optimization problem

Corresponding Author: Alongkorn Lamom, Faculty of Engineering, Chulalongkorn University, 10330, Thailand 
Am. J. Applied Sci., 5 (8): 943-951, 2008
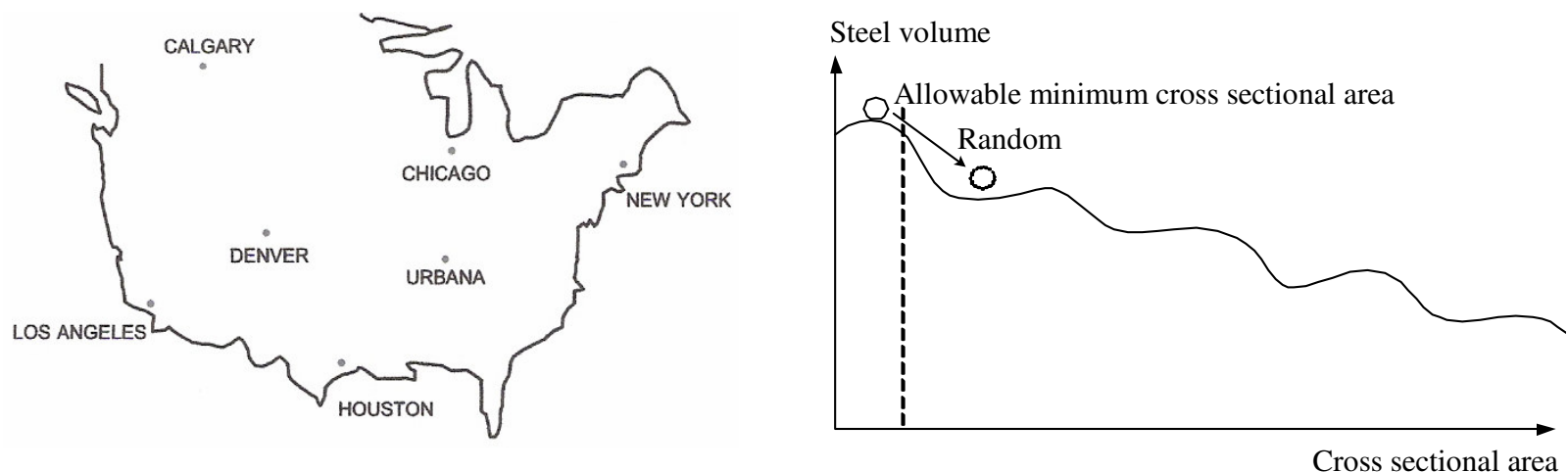

Fig. 2: Traveling salesman problem

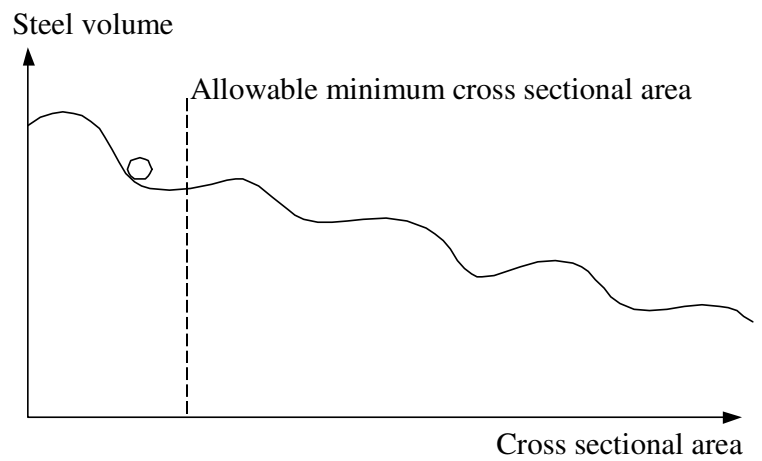

Fig. 4: Reducing material size

which has shortest distance is the best solution. However, this method is not practically effective when there are many cities. For example, if 100 cities are goaled, there are $4.67 \times 10^{155}$ traveling paths. In this case, it will take long time to find the optimal answer.

A better method to find the shortest path is to use the knowledge of problem understanding to guess the answer. It is obvious that the next selected city for going should be the nearest city. If the every decisions of city selection are nearest city from the current city, the good answer may be investigated. This is an example of using the knowledge to help solving the problem. The selected path may not be the best answer but it is an acceptable one. Using an uncompleted knowledge to handle a problem or a reasonable guessing is called heuristic.

In the SA, although there are many proposed techniques for predicting feasible zone, answers generated for optimal structural problem is randomized. New answers are generated around the present answer as shown in Fig. 1. Each new answer is then checked if it passes all constraints. In this study, behavior of optimal structural problem is studied and is found to be similar to that shown in Fig. 3 with y-axis is the steel volume and $\mathrm{x}$-axis is the cross sectional area of steel in one group. Trend of the best answer occurs at the left hand side of the graph and locates above the load constraint which is converted to be allowable minimum cross sectional area constraint. This constraint varies with steel cross sectional area.

If the gap between answer and allowable minimum cross sectional area is small, the best answer should be resulted. The proposed algorithm is developed from this knowledge. The algorithm will be demonstrated in the next section. 
Table 1: Heuristics algorithm for material size selection

\begin{tabular}{ll}
\hline 1 & Evaluate the initial state which is the biggest size \\
2.1 & UNTIL a volume of current state and a volume of previous state are equal 2 time continuously DO \\
2.2 & Reduce sizes of materials randomly \\
2.2 .1 & UNTIL size of materials are enough for loads DO \\
2.3 & Increase sizes of materials one step \\
2.3 .1 & Evaluate the new state \\
& Compute the structural volume \\
& IF volume of new state = volume of previous state then \\
& Return new state and quit \\
& ELSE IF the new state is better than the current state \\
& THEN (current state = new state) \\
& ELSE (current state = old state) \\
\hline
\end{tabular}

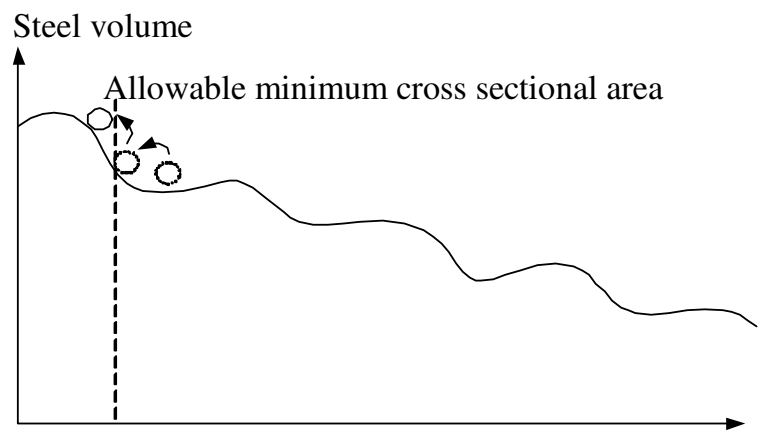

Cross sectional area

Fig. 5: Increasing material size

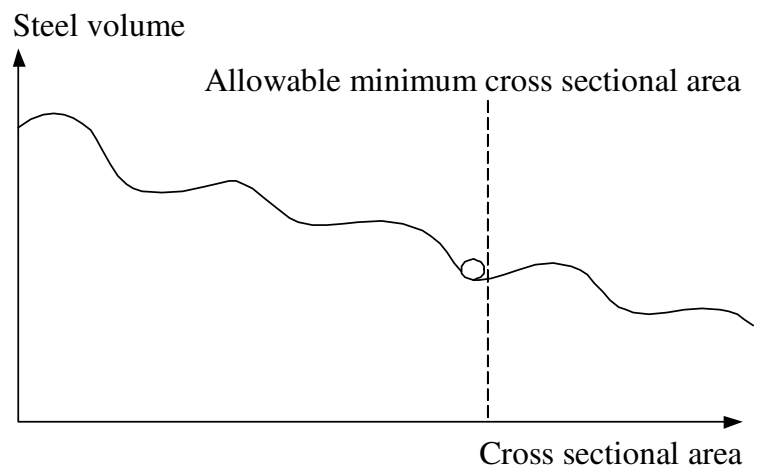

Fig. 6: Algorithm stop

\section{HEURISTIC ALGORITHM FOR MATERIAL SIZE SELECTION}

Firstly, the maximum size from the given material data is assigned to be the started answer. Then a new answer is randomly created by reducing size of material as shown in Fig. 4. If this material size is below the allowable minimum cross sectional area line, i.e. the size does not pass the load constraints. A new answer is created by increasing material size one step. This procedure is repeated until corrected size is obtained as shown at Fig. 5. The algorithm will repeat the process until the steel volume of a new answer does not change for 2 times. The last answer is the best result as shown in Fig. 6.

The Heuristic Algorithm for Material Size Selection is shown in Table 1. Step 1, all members in a structure are assigned to be the biggest size. Step 2 is the stopping evaluation. If the steel volume of the new answer is repeated twice, the algorithm will stop and the last best answer is a final result.In case that the steel volume can be reduced, Step 2.1 will operate. All member sizes are reduced randomly in this step. Members having the same group number, however, will have the same size. Next step is the constraint examination. In step 2.2, all members are verified if their sizes are large enough for load constraints. If material size of any member group is unacceptable, material size of that member group is increased one size at step 2.2.1 until all member sizes pass the load constraints. In step 2.3, the new answer is evaluated. If the new answer is better than the previous one, the current answer is replaced by the new answer. If the new answer is equal to the current answer, the new answer is assigned to be an initial answer for the next loop. These processes at step 2 are recursively operated until the constraint at step 2 is qualified. Then, the last best answer is set to be the final result.

\section{NUMERICAL EXAMPLE}

Three truss structures are used to verify the proposed algorithm. Each example is studied by using a commercial steel design software and two algorithms. The selected steel design software is Multiframe $4 \mathrm{D}^{[8]}$. This program is a specialized steel design software widely used in civil engineering. The two algorithms are the Simulated Annealing Algorithm (SA) and the Heuristic Algorithm for Material Size Selection 
Am. J. Applied Sci., 5 (8): 943-951, 2008

\begin{tabular}{|c|c|c|c|c|c|}
\hline Number & Section & $\begin{array}{l}\text { Outside diameter } \\
(\mathrm{mm})\end{array}$ & $\begin{array}{l}\text { Thickness } \\
(\mathrm{mm})\end{array}$ & Area $\left(\mathrm{m}^{2}\right)$ & $\begin{array}{l}\text { Radius of } \\
\text { gyration (mm) }\end{array}$ \\
\hline 1 & $\mathrm{P} 15 \times 2$ & 21.7 & 2 & 0.000124 & 7 \\
\hline 2 & $\mathrm{P} 20 \times 2$ & 27.2 & 2 & 0.000158 & 8.9 \\
\hline 3 & $\mathrm{P} 20 \times 2.3$ & 27.2 & 2.3 & 0.000180 & 8.8 \\
\hline 4 & P25 $\times 2.3$ & 34.0 & 2.3 & 0.000229 & 11.2 \\
\hline 5 & $\mathrm{P} 32 \times 2.3$ & 42.7 & 2.3 & 0.000292 & 14.3 \\
\hline 6 & $\mathrm{P} 40 \times 2.3$ & 48.6 & 2.3 & 0.000335 & 16.4 \\
\hline 7 & $\mathrm{P} 40 \times 2.8$ & 48.6 & 2.8 & 0.000403 & 16.2 \\
\hline 8 & P50x2.3 & 60.5 & 2.3 & 0.000421 & 20.6 \\
\hline 9 & $\mathrm{P} 40 \times 3.2$ & 48.6 & 3.2 & 0.000456 & 16.1 \\
\hline 10 & P50×3.2 & 60.5 & 3.2 & 0.000576 & 20.3 \\
\hline 11 & P65×2.8 & 76.3 & 2.8 & 0.000647 & 26 \\
\hline 12 & P50x4 & 60.5 & 4.0 & 0.000710 & 20 \\
\hline 13 & $\mathrm{P} 65 \times 3.2$ & 76.3 & 3.2 & 0.000735 & 25.6 \\
\hline 14 & P80x2.8 & 89.1 & 2.8 & 0.000759 & 30.5 \\
\hline 15 & $\mathrm{P} 80 \times 3.2$ & 89.1 & 3.2 & 0.000864 & 30.4 \\
\hline 16 & P90×3.2 & 101.6 & 3.2 & 0.000989 & 34.8 \\
\hline 17 & $\mathrm{P} 100 \times 3.2$ & 114.3 & 3.2 & 0.001117 & 39.3 \\
\hline 18 & $\mathrm{P} 90 \times 4$ & 101.6 & 4.0 & 0.001226 & 34.5 \\
\hline 19 & $\mathrm{P} 125 \times 3.6$ & 139.8 & 3.6 & 0.001540 & 48.2 \\
\hline 20 & $\mathrm{P} 100 \times 4.5$ & 114.3 & 4.5 & 0.001552 & 38.9 \\
\hline 21 & $\mathrm{P} 125 \times 4$ & 139.8 & 4.0 & 0.001707 & 48 \\
\hline 22 & $\mathrm{P} 125 \times 4.5$ & 139.8 & 4.5 & 0.001913 & 47.9 \\
\hline 23 & P150x4.5 & 165.2 & 4.5 & 0.002272 & 56.8 \\
\hline 24 & $P 150 \times 5$ & 165.2 & 5 & 0.002516 & 56.7 \\
\hline 25 & P125x6 & 139.8 & 6 & 0.002522 & 47.4 \\
\hline 26 & P200x4.5 & 216.3 & 4.5 & 0.002994 & 74.9 \\
\hline 27 & $\mathrm{P} 150 \times 6$ & 165.2 & 6 & 0.003001 & 56.3 \\
\hline 28 & P200×5.8 & 216.3 & 5.8 & 0.003836 & 74.5 \\
\hline 29 & P200x7 & 216.3 & 7 & 0.004603 & 74 \\
\hline
\end{tabular}

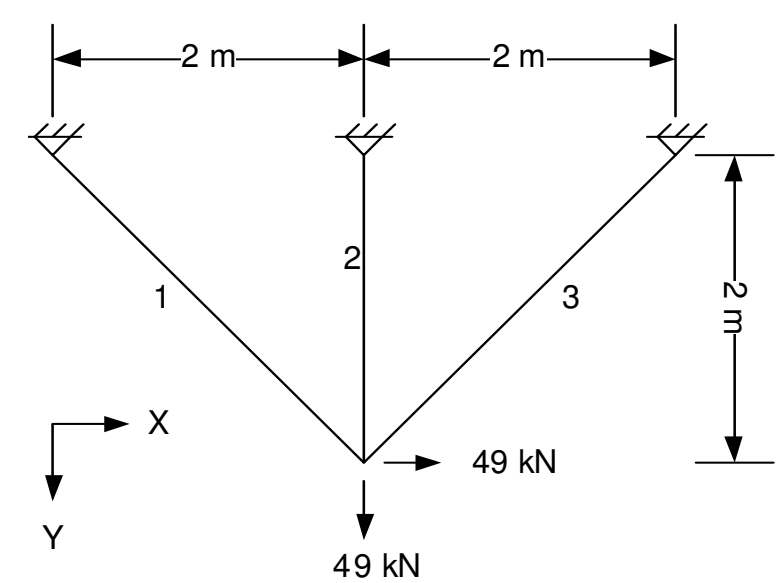

Fig. 7: A 3 bar planar truss (Example 1)

(HAMSS). These algorithms are implemented in SUTStructure ${ }^{[9,10]}$. SUT structor is an education structural analysis software used to analyze two dimensional truss and frame structures. Structural design criteria used in the Multiframe and the SA is the Allowable Stress Design (ASD) given in the AISC 1989 specification. The HAMSS algorithm however uses the ASD from both the AISC 1989 and AISC 2005 specifications ${ }^{[11]}$.
Table 3: Group information (Example 1)

\begin{tabular}{ll}
\hline Group & Members \\
\hline 1 & 1,3 \\
2 & 2 \\
\hline
\end{tabular}

Steel shape used in the study is the hollow round steel as listed in Table 2. There are 29 sizes. Modulus of Elasticity, E, is $196 \times 10^{6} \mathrm{kN} \mathrm{m}^{-2}\left(2 \times 10^{10} \mathrm{~kg} \mathrm{~m}^{2}\right)$ and yield stress, $F_{y}$, is $245000 \mathrm{kN} \mathrm{m}^{-2}\left(25000000 \mathrm{~kg} \mathrm{~m}^{-2}\right)$.

Example 1: The first example is a typical planar truss structure. The structure is a 3 bar planar truss. All members in the structure are connected by hinged connections. Load $49 \mathrm{kN}(5000 \mathrm{~kg})$ acts along both X and $\mathrm{Y}$-axis as shown in Fig. 7. Material group information is given in Table 3. Materials sizes are divided into 2 groups. Material sizes of member 1 and member 3 are equal and assigned to be group 1 while member 2 is different and assigned to be group 2 .

The problem optimization is studied by using the Multiframe software program, the SA and the HAMSS algorithms. In the Multiframe, the optimal steel design required 2 important commands, the analysis and the design commands. To find the best answer, the analysis command will be called first then followed by the design command. These processes will be repeated until sizes of the designed steel do not change. Then the 
Am. J. Applied Sci., 5 (8): 943-951, 2008

Table 4: Results from algorithms (Example 1)

\begin{tabular}{lllll}
\hline Group & $\begin{array}{l}\text { Multiframe } \\
\text { (ASD1989) }\end{array}$ & $\begin{array}{l}\text { SA } \\
\text { (ASD1989) }\end{array}$ & $\begin{array}{l}\text { HAMSS } \\
\text { (ASD1989) }\end{array}$ & $\begin{array}{l}\text { HAMSS } \\
\text { (ASD2005) }\end{array}$ \\
\hline 1 & $\mathrm{P} 40 \times 2.8$ & $\mathrm{P} 40 \times 2.8$ & $\mathrm{P} 40 \times 2.8$ & $\mathrm{P} 40 \times 2.8$ \\
2 & $\mathrm{P} 15 \times 2$ & $\mathrm{P} 15 \times 2$ & $\mathrm{P} 15 \times 2$ & $\mathrm{P} 15 \times 2$ \\
Volume & $2528 \mathrm{~cm}^{3}$ & $2528 \mathrm{~cm}^{3}$ & $2528 \mathrm{~cm}^{3}$ & $2528 \mathrm{~cm}^{3}$ \\
\hline
\end{tabular}

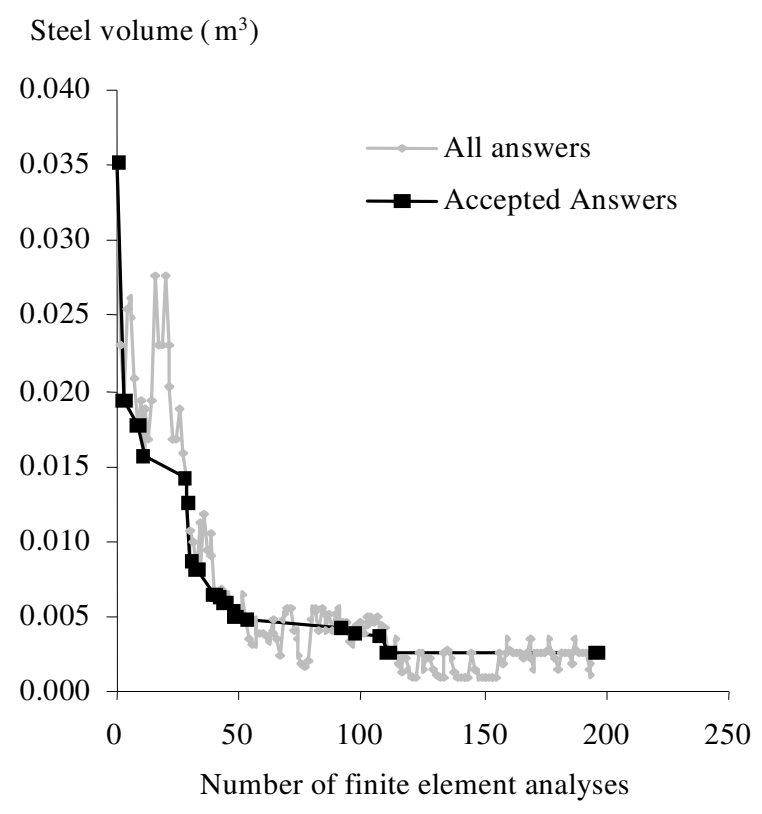

Fig. 8: Convergent graph of the SA (Example 1)

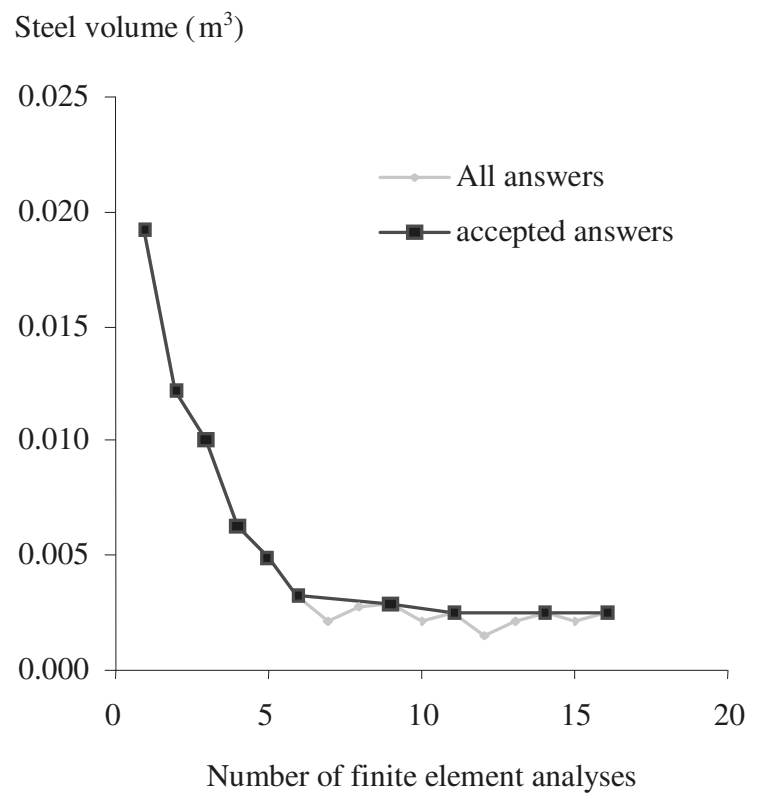

Fig. 9: Convergent graph of the HAMSS (Example 1)

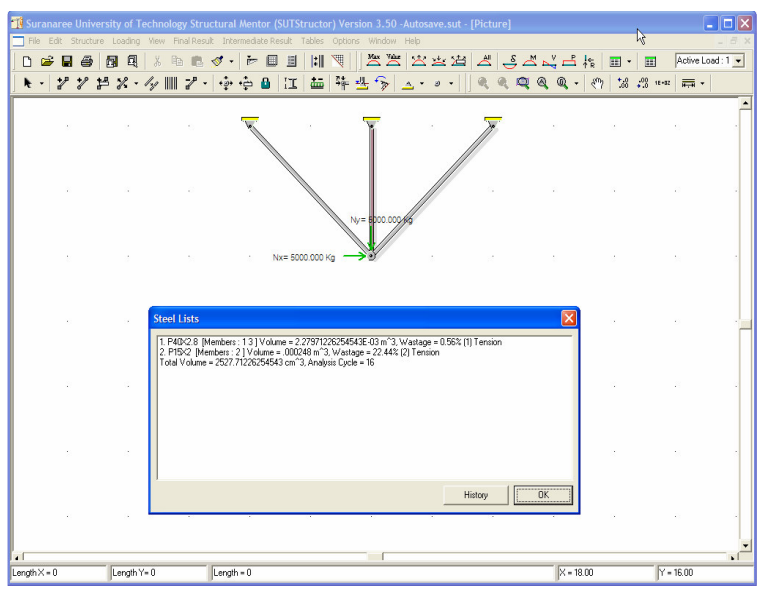

Fig. 10: Results from the implemented program (Example 1)

biggest steel size in each group is selected to be the selected size of that group. From the study, the optimum steel volume of the structure is $2528 \mathrm{~cm}^{3}$. Selected steel sizes are shown in Table 4.

In the SA, the design criteria used with this algorithm is based on the AISC 1989. The example is run with this algorithm for 25 times. The best design from these results is selected to be the answer. To obtain the optimal answer, the SA uses 196 finite element analyses. The optimum steel volume of the structure designed by the SA is $2528 \mathrm{~cm}^{3}$. Selected steel sizes are listed in Table 3 . The intermediated results from log file are plotted as convergent graph in Fig. 8. It should be noted that both the Multiframe and the SA algorithm yield the same optimum steel volume.

In the HAMSS, both AISC 1989 and AISC 2005 (ASD) are studied. The example is tested with this algorithm for 25 times. The optimum steel volume of the structure designed by the HAMSS with both AISC $1989^{-1}$ and AISC $2005^{-1}$ (ASD) is $2528 \mathrm{~cm}^{3}$. The intermediated results from the HAMSS for AISC 2005 (ASD) standard are plotted and shown in Fig. 9. The gray points show all answers generated in the process of trial to find the optimal solution. The dark points on the graph are accepted answers. The HAMSS used only 16 finite element analyses. The final results reported from the implemented program are demonstrated in Fig. 10. 


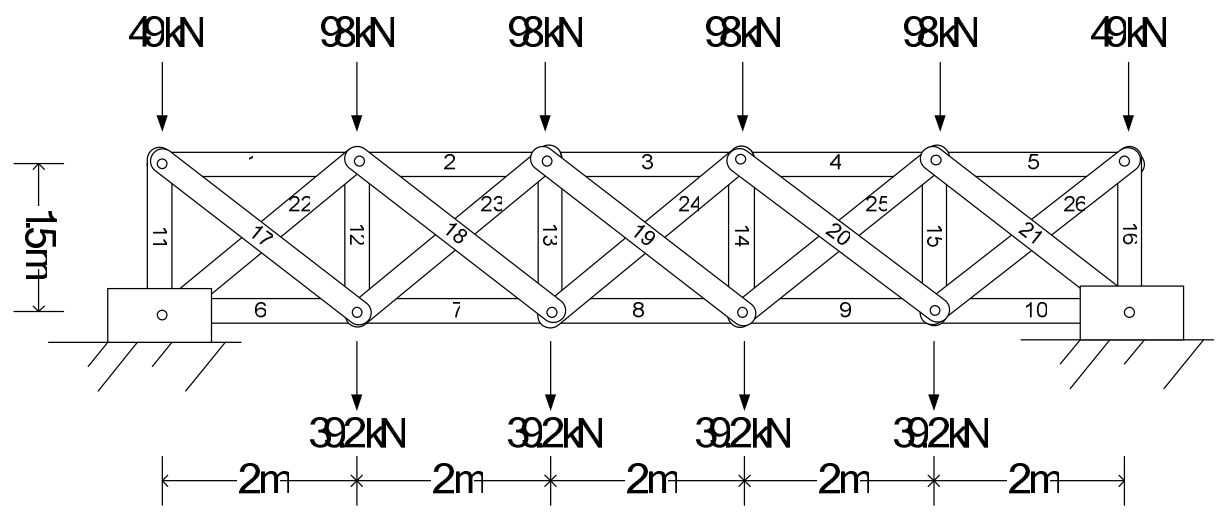

Fig. 11: A 26 bar planar truss (Example 2)

Table 5: Group information (Example 2)

\begin{tabular}{ll}
\hline Group & Members \\
\hline 1 & $1,5,6-10,11-16$ \\
2 & $2,3,4$ \\
3 & $17-20,23-26$ \\
4 & 21,22 \\
\hline
\end{tabular}

Steel volum $\left(^{3}{ }^{3}\right)$

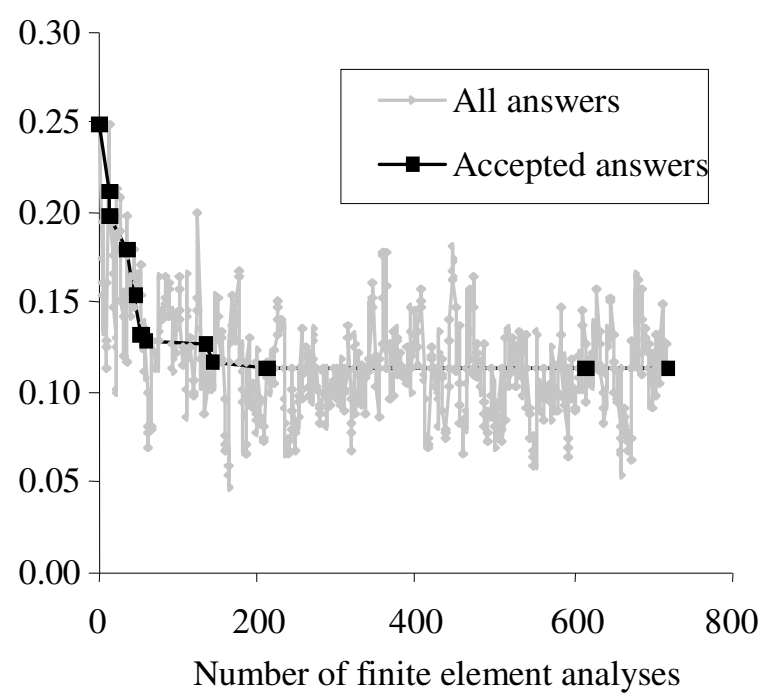

Fig. 12. Convergent graph of the SA (Example 2)
HAMSS required only 16 finite element analyses when compares to 269 finite element analyses used in the SA. Table 4 reports steel volume and selected steel sizes designed by the Multiframe, the SA and the HSMSS algorithms. All design techniques give the same results. However, it should be pointed out that the

Example 2: The second example is a 26 bar planar truss with joint loads as shown in Fig. 11. All connections in the structure are hinged connections. The truss is also pin supported at both ends. The structure is $1.5 \mathrm{~m}$ high and $10 \mathrm{~m}$ long.

Material sizes in the structure are assigned into 4 groups. Information of members using the same steel size is shown in Table 5.

The steel volume of the structure obtained from the Multiframe is $103289 \mathrm{~cm}^{3}$. The selected steel sizes are shown in Table 6.

In the $\mathrm{SA}$, the example is run with this algorithm for 25 times. The best design from these results is selected to be the answer. Fig. 12 shows convergent performance of the SA. To find the optimal answer in this example, the SA requires 719 finite element analyses. The optimum steel volume of the structure designed by the SA is $112785 \mathrm{~cm}^{3}$. Selected steel sizes are shown in Table 6. According to the information in Fig. 12, it can be seen that many answers are generated but they are mostly rejected. Most of them do not pass steel design criteria. Many rejections cause much

Table 6: Results from algorithms (Example 2)

\begin{tabular}{|c|c|c|c|c|}
\hline Group & $\begin{array}{l}\text { Multiframe } \\
\text { (ASD1989) }\end{array}$ & $\begin{array}{l}\text { SA } \\
\text { (ASD1989) }\end{array}$ & $\begin{array}{l}\text { HAMSS } \\
\text { (ASD1989) }\end{array}$ & $\begin{array}{l}\text { HAMSS } \\
(\text { ASD2005) }\end{array}$ \\
\hline$\overline{1}$ & $\mathrm{P} 100 \times 3.2$ & P125x4.5 & P80x3.2 & P90×3.2 \\
\hline 2 & $\mathrm{P} 200 \times 7$ & $\mathrm{P} 200 \times 5.8$ & $P 200 \times 7$ & $\mathrm{P} 200 \times 5.8$ \\
\hline 3 & $\mathrm{P} 125 \times 3.6$ & $\mathrm{P} 125 \times 3.6$ & $\mathrm{P} 100 \times 3.2$ & $\mathrm{P} 100 \times 3.2$ \\
\hline 4 & $\mathrm{P} 200 \times 5.8$ & $\mathrm{P} 200 \times 4.5$ & $\mathrm{P} 200 \times 5.8$ & $\mathrm{P} 200 \times 4.5$ \\
\hline Volume & $103289 \mathrm{~cm}^{3}$ & $112785 \mathrm{~cm}^{3}$ & $89010 \mathrm{~cm}^{3}$ & $83073 \mathrm{~cm}^{3}$ \\
\hline
\end{tabular}


St eel volum e $\left(\mathrm{m}^{3}\right)$

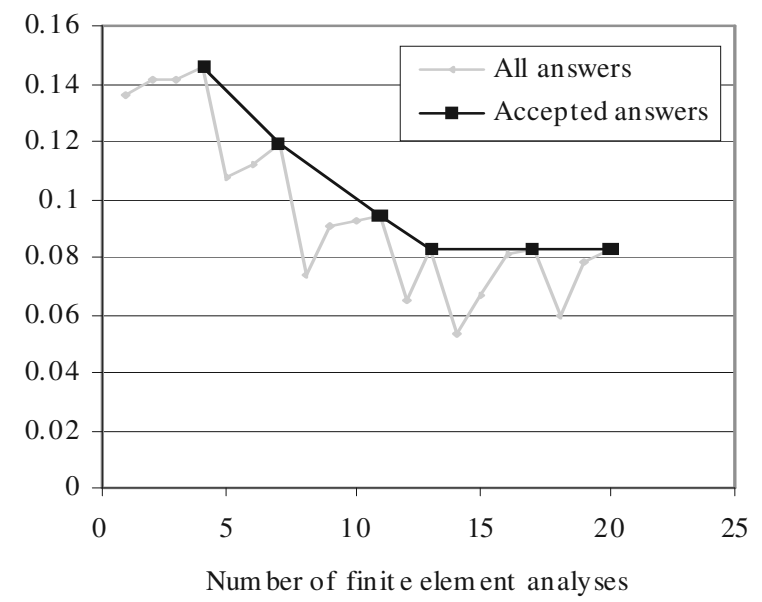

Fig. 13: Convergent graph of the HAMSS (Example 2)

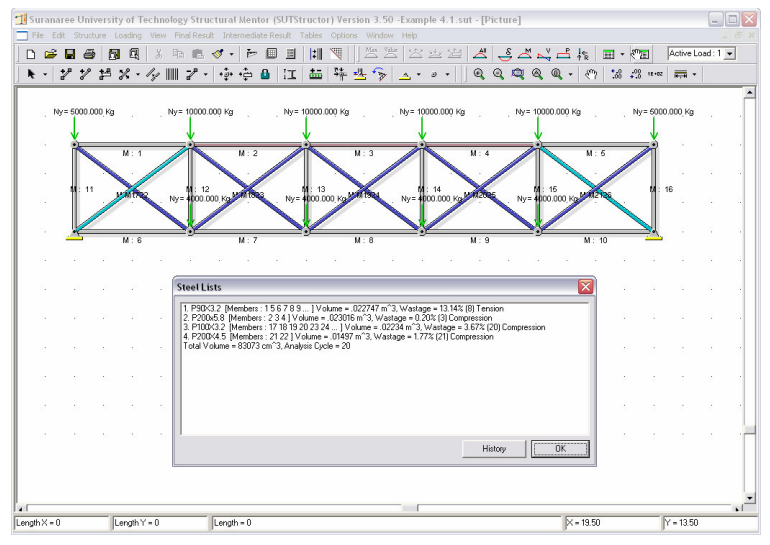

Fig. 14: Results from the implemented program (Example 2)

Table 7: Group information (Example 3)

\begin{tabular}{ll}
\hline Group & Members \\
\hline 1 & $1-7$ \\
2 & $8-14$ \\
3 & $15-22$ \\
4 & $23-25,28-30$ \\
5 & 26,27 \\
\hline
\end{tabular}

Steel volume $\left(\mathrm{m}^{3}\right)$

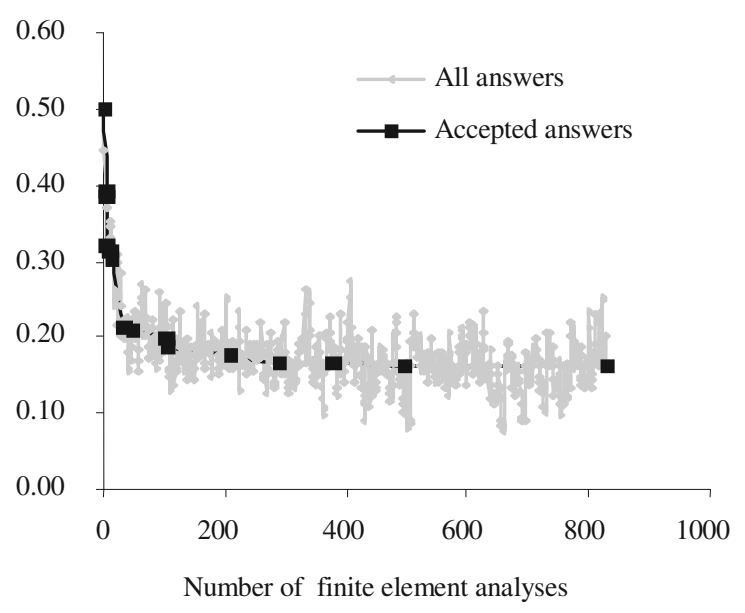

Fig. 15: Convergent graph of the SA (Example 3)

computation time for answer validations. These times are totally waste.

In the HAMSS, The optimum steel volume of the structure designed using the ASD 1989 standard is $89010 \mathrm{~cm}^{3}$ and it requires only 20 finite element analyses. Also in the HAMSS with ASD 2005, the optimum steel volume of the structure is $83073 \mathrm{~cm}^{3}$ and it spends only 20 finite element analyses to get the answer. These results show that the HAMSS is more powerful than the SA in term of number of finite element analyses. The convergent performance graph of HAMSS for the ASD 2005 version is shown in Fig. 13. Only 14 rejected answers are created. The final results reported from the implemented program are presented in Fig. 14.

Table 6 shows the optimum structural steel volume and selected material sizes designed by each technique.

According to information in Table 6, the optimum steel volumes of the structure designed using both versions of the HAMSS, AISC $1989^{-}$and AISC $2005^{-1}$, are also significantly better than the optimum steel volume of the structure designed using the Multiframe and the SA.

Table 8: Result from algorithms (Example 3)

\begin{tabular}{lllll}
\hline Group & $\begin{array}{l}\text { Multiframe } \\
\text { (ASD1989) }\end{array}$ & $\begin{array}{l}\text { SA } \\
\text { (ASD1989) }\end{array}$ & $\begin{array}{l}\text { HAMSS } \\
(\text { ASD1989) }\end{array}$ & $\begin{array}{l}\text { HAMSS } \\
\text { (ASD2005) }\end{array}$ \\
\hline 1 & $\mathrm{P} 200 \times 4.5$ & $\mathrm{P} 150 \times 6$ & $\mathrm{P} 200 \times 4.5$ & $\mathrm{P} 200 \times 4.5$ \\
2 & $\mathrm{P} 125 \times 3.6$ & $\mathrm{P} 125 \times 3.6$ & $\mathrm{P} 125 \times 3.6$ & $\mathrm{P} 125 \times 3.6$ \\
3 & $\mathrm{P} 65 \times 3.2$ & $\mathrm{P} 80 \times 2.8$ & $\mathrm{P} 65 \times 3.2$ & $\mathrm{P} 65 \times 3.2$ \\
4 & $\mathrm{P} 65 \times 2.8$ & $\mathrm{P} 40 \times 3.2$ & $\mathrm{P} 40 \times 3.2$ & $\mathrm{P} 40 \times 3.2$ \\
5 & $\mathrm{P} 90 \times 3.2$ & $\mathrm{P} 80 \times 2.8$ & $\mathrm{P} 80 \times 2.8$ & $\mathrm{P} 80 \times 2.8$ \\
Volume & $169277 \mathrm{~cm}^{3}$ & $163074 \mathrm{~cm}^{3}$ & $162485 \mathrm{~cm}^{3}$ & $162485 \mathrm{~cm}^{3}$ \\
\hline
\end{tabular}




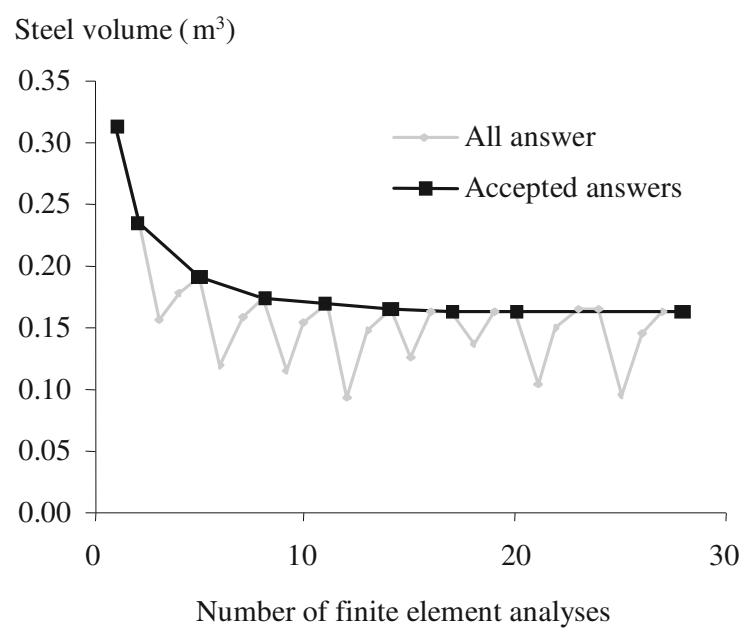

Fig. 16: Convergent graph of the HAMSS (Example 3)

Example 3: The third example is a 30 bar planar truss with joint loads as shown in Fig. 15. The structure is $5.5 \mathrm{~m}$ high and $28 \mathrm{~m}$ long. The structure is pin supported at both ends. All connections in the structure are hinged connections. Material sizes in the structure are assigned into 5 groups. Members that use the same steel size are grouped and shown in Table 7.

The example is computed by the Multiframe software, the SA and both versions of the HAMSS. The optimum steel volume of the structure designed by the Multiframe is $169277 \mathrm{~cm}^{3}$. Selected steel sizes are shown in Table 8.

In the SA, the design criteria used with this algorithm is based on the AISC 1989. The example is run with this algorithm for 25 times. The best design from these results is selected to be the answer. To obtain the optimal answer, the SA uses 829 finite element analyses. The optimum steel volume of the structure designed by the SA is $162485 \mathrm{~cm}^{3}$. Selected steel sizes are listed in Table 8 . The intermediated results from log file are plotted as convergent graph in Fig. 13. The dark points are the accepted answers and the gray points are the rejected answers. This information show that the SA can find the optimal solution, but many waste answers are created before the best answer is found. Most answers are rejected because either the answers do not pass the constraints or the answers are not better than the previous answer.

In the HAMSS, both AISC 1989 and AISC 2005 (ASD) are studied. The optimum steel volume of the structure which is designed by the HAMSS with both AISC $1989^{-1}$ and AISC $2005^{-1}$ (ASD) is $162485 \mathrm{~cm}^{3}$. The intermediated results from the HAMSS for AISC 2005 (ASD) standard are graphically shown in Fig. 16.
It should be noted that the number of finite element analyses in Fig. 16 is less than the number of finite element analyses in Fig. 15. Final results reported from the implemented program based on HAMSS (AISC $2005^{-1}$ ) is shown in Fig. 17.

Table 8 shows the optimum structural steel volume and selected material size designed by each technique.

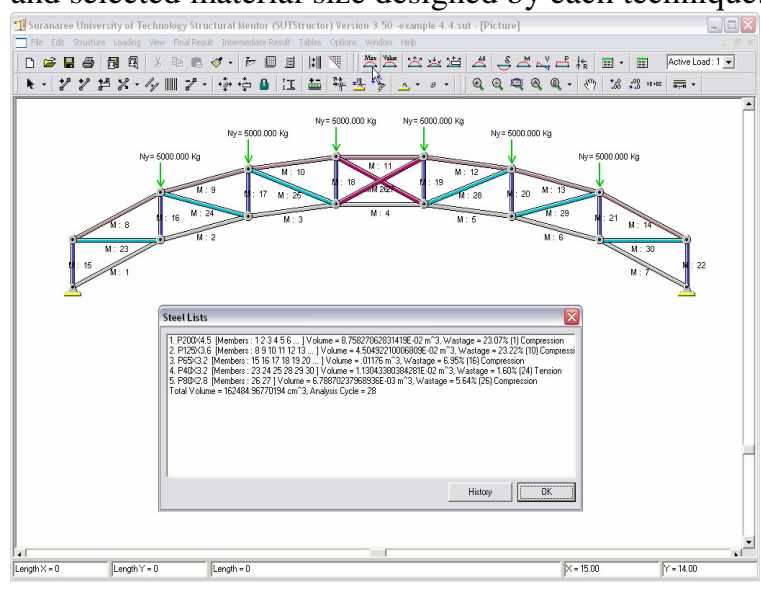

Fig. 17: Results from the implemented program (Example 3)

From the study, the optimum steel volumes of the structure designed by both versions of the HAMSS are better than the SA. In addition, the HAMSS with AISC 2005 specifications requires only 28 finite element analyses when compares to 829 analyses used in the SA.

\section{DISCUSSION}

The paper proposes a new algorithm to handle discrete variable structural optimization problems. Since the proposed algorithm is developed by using knowledge of problem behavior, it is called the Heuristic Algorithm for Material Size Selection (HAMSS). The proposed algorithm is decrypted and evaluated. Three examples of planar steel truss are tested with the Simulated Annealing Algorithm (SA), the proposed algorithm (HAMSS) and a conventional steel design software (Multiframe). Results from the study show that both the SA and the HAMSS can efficiently optimize steel volume of planar truss structures. However, the HAMSS is more effective because it significantly spends less number of finite element analysis cycles when compares to the SA. In addition, any intricate mathematical function is not required for HAMSS. Hence, the HAMSS is an 
efficient optimization technique which is easy for understanding and simple for implementation.

In the future, the HAMSS would be used to solve other problems which are similar to the optimal discrete structural design problem. The other types of structural material and other types of structure will be tested with HAMSS.

\section{REFERENCES}

1. Kalyanmoy, D. and S. Gulati, 2001. Design of truss-structures for minimum weight using genetic algorithms. Finite element in analysis and design, 37: 447-465.

2. Chai, S. and S. Huanchun, 1997. A combinatorial algorithm for the discrete optimization of structures. Appl. Math. and mech., 18: 847-856.

3. Chen, G.S., R.J. Bruno and M. Salama, 1991. Optimal placement of active passive $\mathrm{e}^{-1}$ members in truss structures using simulated annealing. AIAA, 29: 1327-1334.

4. Szewczyk, Z. and P. Hajela, 1993. Neural network approximation in a simulated annealing based optimal structural design. Structural and Multidisciplinary Optimization, 5: 159-165.
5. Bennage, W.A. and A.K. Dhingra, 1995. Single and multiobjective structural optimization in discrete-continuous variables using simulated annealing. Int. J. Numerical Method in Eng., 38: 2753-2773.

6. Ting-Yu, C. and S. Jyh-Jye, 2002. Efficiency improvement of simulated annealing in optimal structural designs. Advances in Eng. Software, 33: 675-680.

7. Boonserm, K., 2003. Artificial Intelligence, pp: 16-17.

8. Formation Design Systems. Multiframe4D, http://www.formsys.com/multiframe

9. Alongkorn, L. and T. Bisarnsin, 2002. Structural Analysis Software for Education in Proceeding of the 8th National convention on civil engineering, Thailand, pp: 119-123.

10. Alongkorn, L. and W. Rivepiboon, 2005. A Nodal Numbering Algorithm for 2D Structural Simulation. ECTI Transactions on Computer and Information Tech., 1: 108-116.

11. AISC, 2005. Specification for structural steel buildings, American Institute of Steel Construction. 